\title{
REM sleep behavior disorder preceding other aspects of synucleinopathies by up to half a century
}

D.O. Claassen, MD

K.A. Josephs, MD, MST

J.E. Ahlskog, MD, PhD

M.H. Silber, MB, ChB

M. Tippmann-Peikert, MD

B.F. Boeve, MD

Address correspondence and reprint requests to Dr. Bradley F. Boeve, Department of Neurology, Mayo Clinic, 200 1st St SW, Rochester, MN 55905 bboeve@mayo.edu

\section{ABSTRACT}

Background: Idiopathic REM sleep behavior disorder (RBD) may be the initial manifestation of synucleinopathies (Parkinson disease [PD], multiple system atrophy [MSA], or dementia with Lewy bodies [DLB]).

Methods: We used the Mayo medical records linkage system to identify cases presenting from 2002 to 2006 meeting the criteria of idiopathic RBD at onset, plus at least 15 years between RBD and development of other neurodegenerative symptoms. All patients underwent evaluations by specialists in sleep medicine to confirm RBD, and behavioral neurology or movement disorders to confirm the subsequent neurodegenerative syndrome.

Results: Clinical criteria were met by 27 patients who experienced isolated RBD for at least 15 years before evolving into PD, PD dementia (PDD), DLB, or MSA. The interval between RBD and subsequent neurologic syndrome ranged up to 50 years, with the median interval 25 years. At initial presentation, primary motor symptoms occurred in 13 patients: 9 with PD, 3 with PD and mild cognitive impairment $(\mathrm{MCI})$, and 1 with PDD. Primary cognitive symptoms occurred in 13 patients: 10 with probable DLB and 3 with $\mathrm{MCl}$. One patient presented with primary autonomic symptoms, diagnosed as MSA. At most recent follow-up, 63\% of patients progressed to develop dementia (PDD or DLB). Concomitant autonomic dysfunction was confirmed in $74 \%$ of all patients.

Conclusions: These cases illustrate that the $\alpha$-synuclein pathogenic process may start decades before the first symptoms of PD, DLB, or MSA. A long-duration preclinical phase has important implications for epidemiologic studies and future interventions designed to slow or halt the neurodegenerative process. Neurology ${ }^{\circledR}$ 2010;75:494-499

GLOSSARY

DLB = dementia with Lewy bodies; $\mathbf{M C I}=$ mild cognitive impairment; $\mathbf{M S A}=$ multiple system atrophy; PD = Parkinson disease; $\mathbf{P D}-\mathbf{M C I}=$ PD with associated mild cognitive impairment; $\mathbf{P D D}=$ Parkinson disease dementia; $\mathbf{P S G}=$ polysomnogram; RBD = REM sleep behavior disorder.

REM sleep behavior disorder (RBD) is a parasomnia characterized by recurrent dream enactment with excessive motor activity. ${ }^{1}$ RBD is now recognized to be a manifestation of the $\alpha$-synucleinopathies Parkinson disease (PD), multiple system atrophy (MSA), and dementia with Lewy bodies (DLB). ${ }^{1-4}$ In some patients, RBD precedes the development of these neurodegenerative syndromes. ${ }^{2,5,6}$ The first study to document the relationship of RBD and these neurodegenerative disorders reported that nearly $40 \%$ of patients with isolated, idiopathic RBD later went on to develop a parkinsonian disorder after a mean of 12.7 years. ${ }^{5}$ Subsequent series have confirmed similar findings, with typical mean intervals from RBD to PD, DLB, or MSA around a decade..$^{2-4,6}$

During routine clinical evaluations, we have noticed anecdotes of RBD symptomatology decades before presentation to a neurologist. In fact, some of the most compelling histories involve RBD symptoms first noticed during a wedding honeymoon. If frequently documented, this would suggest that these $\alpha$-synucleinopathies may sometimes have extremely long durations, with the neuro- 
degenerative process beginning much earlier in life. To explore this further, we sought to collect a cohort of patients who had histories of RBD predating onset of clinical PD, DLB, or MSA by more than 15 years. In reviewing the clinical outcomes of these patients, we sought to include a wide range of data including cognitive, autonomic, and motor manifestations.

METHODS In this convenience series, we used the Mayo Clinic Medical Records Linkage System to identify patients with PD (including a diagnosis of PD, PD plus MCI, or PD plus dementia $[\mathrm{PDD}]$ ), DLB (including cases diagnosed with DLB and MCI plus concurrent parkinsonism), or MSA, who were evaluated during a 5-year period (2002-2006). These patients met the following criteria: 1) idiopathic RBD at onset; 2) at least 15 years between RBD onset and development of other neurodegenerative symptoms (autonomic dysfunction, parkinsonism, or cognitive impairment); and 3) evaluations by Mayo specialists in Sleep Medicine to confirm RBD, and in one or both sections of Behavioral Neurology and Movement Disorders to confirm the subsequent neurodegenerative syndrome. Clinical history was considered positive if the behavior met diagnostic criteria B for $\mathrm{RBD}$, defined as abnormal, flailing movements occurring during sleep, with sleep-related injuries, or movements that are potentially injurious or disruptive. ${ }^{7}$ Symptoms of physical activity during sleep were provided by the patient and bed partner. The diagnosis of probable RBD was based on history and evaluation by a specialist in sleep medicine while definite RBD was based on polysomnographic confirmation.

The clinical findings, neuropsychological testing, and neuroimaging and neuropathologic results (when available) were obtained from the medical record. A diagnosis of DLB was based on consensus criteria ${ }^{8}$ including, but not limited to, recurrent fully formed visual hallucinations, spontaneous parkinsonism (resting tremor, bradykinesia, cogwheel rigidity, and postural instability), fluctuating cognition (changes in the degree of organized and logical thinking, from one time period to another ${ }^{9}{ }^{10}$ ), and presence of RBD. Those with the diagnosis of PD met UK Brain Bank criteria. ${ }^{11}$ PDD was defined as symptoms of PD present for at least 1 year prior to development of dementia. ${ }^{12} \mathrm{~A}$ diagnosis of MSA was confirmed using consensus criteria. ${ }^{13}$ Detailed neuropathologic analysis was performed on all patients who had died and undergone autopsy.

Standard protocol approvals, registrations, and patient consents. Approval was received from the Mayo Clinic Institutional Review Board for this study.

RESULTS Patient population. Of the 550 patients identified over the 5-year period with RBD plus 1 of the 3 disorders of interest, 256 were classified as PD, PD plus MCI, or PDD; 224 were classified as DLB or MCI plus concurrent parkinsonism; and 75 were classified as MSA. Twenty-seven (4.9\%) of these 550 patients met the criterion of $>15$-year RBD history before other neurodegenerative disease symptoms, of which 13 were PD, PD plus MCI, or PDD; 13 were DLB/MCI plus parkinsonism; and 1 was MSA.
Of the 27 patients, 24 (89\%) were male. There were 14 patients who met criteria for definite $\mathrm{RBD}$, and 13 for probable RBD. The median age at presentation for neurologic symptom onset was 72 years $(51-80)$. As shown in the table, the median length of RBD symptoms to neurodegenerative syndrome symptom onset was 25 years (range $15-50$ years), and the median age at onset of RBD symptomatology was 49 years $(21-60)$. All patients had spousal/sleep partner confirmation of both RBD symptomatology and the approximate time of RBD onset. Patients were followed at Mayo Clinic for a mean of 6.2 years (1-11 years). Most of these patients (17/27) were evaluated at the Mayo Clinic Center for Sleep Medicine, primarily because of RBD symptoms.

RBD symptoms and follow-up. In 23 patients, the clinical history of RBD was that of a dream characterized by patients defending themselves from an attacker or running away from an attacking person or animal. The remainder described frightening dreams but could not recall the content. All bed partners confirmed motor behavior during sleep. A story of punching during the dream was provided by $11 \mathrm{pa}-$ tients and their spouses. Other motor behavior during dreams included shouting, leaving the bed, or flailing arm movements. In 6 patients, this behavior was noticed by the spouse early in marriage, either during the honeymoon or soon after. Of note, 8 patients had concomitant hypersomnolence at the time of evaluation.

A formal polysomnogram (PSG) was performed in 17 patients: 16 at our institution and 1 at an outside institution with records available for our review. In this particular patient, polysomnography confirmed RBD. The PSG confirmed RBD in 14 of 16 studies performed at our institution. Of the 2 patients with unconfirmed RBD on PSG, both were highly suspected of RBD. One patient failed to enter REM sleep and thus electromyographic tone could not be assessed, and the other achieved only 5 minutes of stage REM sleep which was not associated with unequivocally increased electromyographic tone. These 2 patients were considered as probable RBD. Additionally, in $50 \%$ of patients with sleep studies (8 patients), the PSG revealed coexisting obstructive sleep apnea, while 65\% (11 patients) had coexisting periodic limb movements of sleep. Of the 10 patients who did not undergo a PSG, reasons listed included patient disinterest, patient time constraints, and the clinician thought the history was sufficient for a diagnosis of RBD without PSG confirmation.

Clinical diagnosis. Initial parkinsonian symptomatology was observed in 13 patients; 9 patients were diag- 


\begin{tabular}{|c|c|c|c|c|c|c|c|c|c|}
\hline Table & tient c & naracteris & & & & & & & \\
\hline Patients & Sex & $\begin{array}{l}\text { Initial } \\
\text { clinical } \\
\text { diagnosis }\end{array}$ & $\begin{array}{l}\text { Final } \\
\text { clinical } \\
\text { diagnosis }\end{array}$ & $\begin{array}{l}\text { Age at RBD } \\
\text { symptom } \\
\text { onset, } y\end{array}$ & $\begin{array}{l}\text { Age at } \\
\text { neurologic } \\
\text { symptom } \\
\text { onset, y }\end{array}$ & $\begin{array}{l}\text { Interval from } \\
\text { RBD to } \\
\text { symptom } \\
\text { onset, y }\end{array}$ & $\begin{array}{l}\text { Age at } \\
\text { PSG, } y\end{array}$ & $\begin{array}{l}\text { Age at } \\
\text { death, } y\end{array}$ & $\begin{array}{l}\text { Pathologic } \\
\text { diagnosis }\end{array}$ \\
\hline \multicolumn{10}{|c|}{ Definite RBD } \\
\hline 1 & M & $\mathrm{MCl}$ & $\mathrm{MCl}$ & 57 & 80 & 23 & 87 & & \\
\hline 2 & M & $\mathrm{MCl}$ & $\mathrm{MCl}$ & 60 & 75 & 15 & 70 & & \\
\hline 3 & $\mathrm{~F}$ & MSA-P & MSA-P & 53 & 70 & 17 & 68 & & \\
\hline 4 & M & $\mathrm{PD}$ & PDD & 21 & 55 & 34 & 61 & & \\
\hline 5 & M & PD & PDD & 44 & 74 & 30 & 74 & 83 & \\
\hline 6 & M & PD & PDD & 21 & 52 & 31 & 77 & 78 & \\
\hline 7 & M & PD-MCI & PD-MCI & 28 & 58 & 30 & 58 & & \\
\hline 8 & M & Prob DLB & Prob DLB & 56 & 76 & 20 & 76 & & \\
\hline 9 & M & Prob DLB & Prob DLB & 54 & 73 & 19 & 73 & & \\
\hline 10 & M & Prob DLB & Prob DLB & 57 & 72 & 15 & 68 & 76 & LBD \\
\hline 11 & M & Prob DLB & Prob DLB & 50 & 78 & 28 & 78 & & \\
\hline 12 & M & Prob DLB & Prob DLB & 59 & 79 & 20 & 79 & 86 & \\
\hline 13 & M & Prob DLB & Prob DLB & 59 & 77 & 18 & 60 & & \\
\hline 14 & M & Prob DLB & Prob DLB & 55 & 79 & 24 & 60 & & \\
\hline \multicolumn{10}{|c|}{ Probable RBD } \\
\hline 15 & M & PD & PD & 27 & 51 & 24 & 59 & & \\
\hline 16 & M & PD & PD & 27 & 77 & 50 & 76 & 81 & \\
\hline 17 & $\mathrm{~F}$ & PD & PD & 46 & 74 & 28 & ND & 81 & \\
\hline 18 & M & PD & PD & 40 & 63 & 23 & ND & & \\
\hline 19 & M & PD & PD-MCI & 49 & 64 & 15 & ND & & \\
\hline 20 & M & PD-MCI & PD-MCI & 24 & 69 & 45 & ND & & \\
\hline 21 & M & PD-MCl & PDD & 23 & 65 & 42 & ND & 75 & \\
\hline 22 & M & PD & PDD & 51 & 70 & 19 & ND & 74 & \\
\hline 23 & M & $\mathrm{MCl}$ & Prob DLB & 35 & 72 & 37 & ND & 76 & \\
\hline 24 & M & PDD & PDD & 57 & 75 & 18 & ND & 86 & \\
\hline 25 & $\mathrm{~F}$ & Prob DLB & Prob DLB & 60 & 75 & 15 & ND & & LBD \\
\hline 26 & M & Prob DLB & Prob DLB & 45 & 60 & 15 & ND & & \\
\hline 27 & M & Prob DLB & Prob DLB & 27 & 51 & 24 & ND & & \\
\hline Median & & & & 49 & 72 & 23 & 71.5 & 79.5 & \\
\hline
\end{tabular}

Abbreviations: $\mathrm{LBD}=$ Lewy body disease; $\mathrm{MCI}=$ mild cognitive impairment; $\mathrm{MSA}-\mathrm{P}$ = parkinsonism-predominant multiple system atrophy; ND = not done; PD = Parkinson disease; PD-MCI = Parkinson disease with mild cognitive impairment; PDD = Parkinson disease dementia; Prob DLB = probable dementia with Lewy bodies; $P S G=$ polysomnogram; RBD = REM sleep behavior disorder.

nosed with PD. At most recent follow-up, PD with associated mild cognitive impairment (PD-MCI) was noted in 3 other patients: 2 with nonamnestic MCI with predominant visual-spatial impairment and 1 with amnestic MCI. One case presented with PDD and was treated for PD 2 years before presenting to our institution.

Cognitive impairment was the presenting complaint in 13 patients. Of the 11 presenting with clear dementia, all had parkinsonism, whereas $9(82 \%)$ had concomitant orthostatic symptoms, 6 (55\%) experienced visual hallucinations, and 7 (64\%) had clinical histories suggestive of cognitive fluctuations.
All 11 were diagnosed with clinically probable DLB based on the criteria of McKeith et al. ${ }^{8}$ MCI was the primary clinical diagnosis in 3 patients. All patients underwent neuropsychological testing. Neuropsychological testing in the 3 patients with MCI revealed deficiencies in multiple domains in 2 patients (language/memory and visual-spatial/memory), while the other patient scored poorly on memory testing and was characterized as amnestic MCI.

Only one patient presented with primary autonomic symptomatology. She was diagnosed with MSA. This case was 1 of the 3 women in the study. 
A majority of patients (85\%) were followed for 3 years or longer. At latest follow-up, 4 patients with PD and 1 patient with PD-MCI developed cognitive impairment resulting in a diagnosis of PDD. Of the 3 patients with MCI, 1 patient progressed to probable DLB. The majority of patients (45\%) at clinical follow-up had a diagnosis of probable DLB. Notably, when accounting for all cases of DLB and PDD, $64 \%$ of patients developed dementia.

Autonomic symptoms and autonomic testing. Autonomic symptoms were common and deserve additional comment; $74 \%$ of patients (20) experienced dysautonomia. This was predominantly expressed as postural related lightheadedness, but also included urinary incontinence or retention, and constipation. Objective evidence of supine-to-erect systolic fall in blood pressure was documented in 16 patients (mean systolic drop was $30 \mathrm{~mm} \mathrm{Hg}$ [range 16-60], with 10 patients having a drop greater than $30 \mathrm{~mm} \mathrm{Hg}$ ).

Formal autonomic studies including adrenergic function, cardiovagal function, and postganglionic sympathetic sudomotor function were performed in 6 patients who had clinical evidence of orthostatism by blood pressure measurements. Five patients had evidence of severe adrenergic failure consistent with orthostatic hypotension on tilt table test; 3 of these patients were clinically diagnosed with PD or PDMCI, while 2 cases were diagnosed with a dementia syndrome, 1 with probable DLB and the other with PDD. One patient had moderate adrenergic failure, and this patient was diagnosed with MSA. Cardiovagal responses were mild to moderately abnormal in all patients with the exception of 1 patient who had a pacemaker. Postganglionic sympathetic sudomotor response was abnormal in all patients.

Functional imaging findings. Two patients underwent SPECT 99mTc imaging; both studies showed markedly asymmetric hypoperfusion of the frontal, parietal, and occipital lobes. The presence of parietal and occipital involvement was considered suggestive of a Lewy body process. One patient was diagnosed with PD-MCI and the other with probable DLB.

Neuropathologic findings. At final review of the clinical records, 10 of 28 patients had died. The median time to death from RBD onset was 37 years (19-57), and from onset of autonomic/cognitive/motor changes was 7 years $(4-26)$; 2 of these patients underwent autopsy. Both brains showed striking evidence of Lewy body disease, with minimal Alzheimer-type pathology changes. The predominant regions affected in these cases were brainstem and limbic areas, and both were characterized pathologically as limbic-predominant Lewy body disease.
DISCUSSION These cases add longitudinal perspective on the evolution of neurodegenerative syndromes characterized by $\alpha$-synuclein neuropathology. Not long ago, the prototypic $\alpha$-synucleinopathy, PD, was estimated to begin about 5-6 years before motor symptom onset, based on imaging ${ }^{14-17}$ or neuropathologic estimates. ${ }^{18}$

However, these estimates were superseded by the recognition that $\mathrm{RBD}$ is an early feature of $\mathrm{PD}$ and in the seminal article, preceded PD motor symptoms by a mean of 12.7 years. ${ }^{5}$ Similarly, the dysautonomic symptom of constipation was significantly associated with later development of PD, and with a mean 10-year latency. ${ }^{19}$ Subsequent series confirmed $\mathrm{RBD}$ preceding PD by around a decade, on average, and extended this to DLB. ${ }^{2,4,6}$ Notably, in these previous RBD series, occasional cases had RBD documented substantially more than a decade before PD onset. Our series now suggests that such cases with very long latencies are relatively frequent. Thus, in this referral-center cohort, 27 patients with PD, DLB, or MSA had clear RBD for more than 15 years, and up to 50 years before the neurodegenerative syndrome clinically manifested.

These findings suggest that PD, DLB, and MSA have very long durations of activity, often with long latencies when the pathogenic process is active, but inapparent or marginally apparent. Thus, the median onset of RBD in this series was age 47.5 years, but as early as age 21 in these syndromes that did not fully present with neurodegenerative syndromes until middle age or beyond.

This long latency is supported by other evidence, and a prolonged premotor period has also been suggested for other aspects of PD. Preexisting anxiety was associated with later development of PD including extension of the analysis to 20 years before parkinsonism onset. ${ }^{20}$ An early-life PD personality has also been noted, although this remains controversial. ${ }^{21}$ These RBD findings are also consistent with studies suggesting that the earliest Lewy pathology involves pontomedullary nuclei $i^{22,23}$ at brainstem levels that include the peri-locus ceruleus region, which is the RBD substrate in rats. ${ }^{1,24}$

Nearly three-fourths of our patients experienced autonomic dysfunction, which was confirmed by formal autonomic studies in 6 . Our results are consistent with previous studies suggesting that dysautonomia may tend to parallel RBD in $\alpha$-synucleinopathy patients. Thus, dysautonomia may be a very early feature, like RBD, as evidenced by the aforementioned development of constipation well before PD motor symptoms. ${ }^{19}$ Autonomic dysfunction may not only precede PD by a long interval, but also DLB. ${ }^{25-27}$ RBD without other neurologic symptomatology has also been 
associated with reduced cardiac (123) I-metaiodobenzylguanidine uptake (MIBG), consistent with the loss of sympathetic terminals. ${ }^{28}$

In our series, $85 \%$ of patients (23/27) experienced at least MCI, and most frank dementia. Almost half of the patients with PD in our study progressed to PDD, and two-thirds of all patients went on to develop a dementia syndrome of either DLB or PDD. The disproportionate association of $\mathrm{RBD}$ with cognitive impairment has previously been noted ${ }^{29}$; thus, in patients with $\mathrm{PD}$ who were selected for absence of dementia, RBD was highly associated with $\mathrm{MCI}$, in contrast to PD without RBD. In another study, RBD was proposed to represent a red flag for progressing cognitive impairment. ${ }^{29,30}$ Why the clinical presence of RBD portends a propensity toward dementia/cognitive impairment is not entirely clear, but might relate to more pervasive Lewy body disease.

In prior series, not all patients who initially present with isolated, idiopathic RBD go on to develop PD, DLB, or MSA. 2,3,6,31 However, the current series documenting very long latencies raises a question whether all patients with RBD would later develop such neurodegenerative syndromes if they lived long enough.

This series of 27 cases was collected over only 5 years, suggesting that these long intervals of RBD preceding motor/cognitive/autonomic symptoms are not rare. However, this was a convenience series from a referral database at a tertiary center, so nothing can be inferred about true incidence or prevalence. In practice, RBD is likely overlooked since clinicians of ten do not ask about dream enactment behavior and patients/family would not intuitively expect this to be relevant to later-developing neurologic syndromes. Hence, true incidence/prevalence would require a prospective cohort study.

These cases illustrate that PD, DLB, and MSA may have extremely long courses, with preclinical periods extending back decades in at least some cases. Thus, in some cases, the pathogenic process may span most of the lifetime. This is relevant to epidemiologic studies investigating exposures. It is also highly relevant to the development of therapies that might slow or halt $\alpha$-synucleinopathy progression, which could be implemented well before the cognitive and motor features are manifest.

\section{DISCLOSURE}

Dr. Claassen is a recipient of the American Academy of Neurology Clinical Research Fellowship. Dr. Josephs receives research support from the Dana Foundation, the NIH R01-DC010367 (PI), and the Morris K. Udall PD Research Center of Excellence NIH/NINDS P50 \#NS40256 (Co-I). Dr. Ahlskog received the Fred Springer Award from the American Parkinson's Disease Association; serves on the editorial boards of Parkinsonism and Related Disorders and Clinical Neuropharmacology; receives royalties from the publication of The Parkinson's Disease Treatment Book (Oxford University Press, 2005), Parkinson's Disease Treatment Guide for Physicians (Oxford University
Press, 2009), Parkinson's Disease and Movement Disorders (Humana Press, 2000), and Surgical Treatment of Parkinson's Disease and Other Movement Disorders (Humana Press, 2003); and receives research support from NIH/ NINDS (P50 NS 40256-R [coinvestigator]). Dr. Silber serves as Deputy Editor of Sleep and on the editorial board of the Journal of Clinical Sleep Medicine; has received honoraria from the American Academy of Neurology, the American Academy of Sleep Medicine, Harvard University and Elsevier Publishing; and has received funding for travel from the American Board of Psychiatry and Neurology. Dr. Tippmann-Peikert reports no disclosures. Dr. Boeve receives royalties from the publication of Behavioral Neurology of Dementia (Cambridge Medicine, 2009); and receives research support from Cephalon, Inc., the NIH (P50 AG16574 [coinvestigator], UO1 AG06786 [coinvestigator], and RO1 AG15866 [coinvestigator]), the Alzheimer's Association, and from the Center for Inherited Disease Research (U24 AG026395 [coinvestigator]).

Received November 18, 2009. Accepted in final form February 17, 2010.

\section{REFERENCES}

1. Boeve BF, Silber MH, Saper CB, et al. Pathophysiology of REM sleep behaviour disorder and relevance to neurodegenerative disease. Brain 2007;130:2770-2788.

2. Boeve BF, Silber MH, Ferman TJ, et al. REM sleep behavior disorder and degenerative dementia: an association likely reflecting Lewy body disease. Neurology 1998;51: 363-370.

3. Postuma RB, Gagnon JF, Vendette M, Fantini ML, Massicotte-Marquez J, Montplaisir J. Quantifying the risk of neurodegenerative disease in idiopathic REM sleep behavior disorder. Neurology 2009;72:1296-1300.

4. Boeve BF, Silber MH, Parisi JE, et al. Synucleinopathy pathology and REM sleep behavior disorder plus dementia or parkinsonism. Neurology 2003;61:40-45.

5. Schenck CH, Bundlie SR, Mahowald MW. Delayed emergence of a parkinsonian disorder in 38\% of 29 older men initially diagnosed with idiopathic rapid eye movement sleep behaviour disorder. Neurology 1996;46:388-393.

6. Iranzo A, Molinuevo JL, Santamaria J, et al. Rapid-eyemovement sleep behaviour disorder as an early marker for a neurodegenerative disorder: a descriptive study. Lancet Neurol 2006;5:572-577.

7. Sateia M. International Classification of Sleep Disorders: Diagnostic and Coding Manual. Westchester, IL: American Academy of Sleep Medicine; 2005.

8. McKeith IG, Dickson DW, Lowe J, et al. Diagnosis and management of dementia with Lewy bodies: third report of the DLB Consortium. Neurology 2005;65:1863-1872.

9. Ferman TJ, Smith GE, Boeve BF, et al. DLB fluctuations: specific features that reliably differentiate DLB from AD and normal aging. Neurology 2004;62:181-187.

10. Molano J, Boeve B, Ferman T, et al. Mild cognitive impairment associated with limbic and neocortical Lewy body disease: a clinicopathological study. Brain 2010;133: $540-556$.

11. Hughes AJ, Daniel SE, Kilford L, Lees AJ. Accuracy of clinical diagnosis of idiopathic Parkinson's disease: a clinico-pathological study of 100 cases. J Neurol Neurosurg Psychiatry 1992;55:181-184.

12. Emre M, Aarsland D, Brown R, et al. Clinical diagnostic criteria for dementia associated with Parkinson's disease. Mov Disord 2007;22:1689-1707.

13. Gilman S, Low PA, Quinn N, et al. Consensus statement on the diagnosis of multiple system atrophy. J Neurol Sci 1999;163:94-98. 
14. Morrish PK, Sawle GV, Brooks DJ. An [18F]dopa-PET and clinical study of the rate of progression in Parkinson's disease. Brain 1996;119:585-591.

15. Morrish PK, Sawle GV, Brooks DJ. The rate of progression of Parkinson's disease: a longitudinal [18F]DOPA PET study. Adv Neurol 1996;69:427-431.

16. Morrish PK, Rakshi JS, Bailey DL, Sawle GV, Brooks DJ. Measuring the rate of progression and estimating the preclinical period of Parkinson's disease with [18F]dopa PET. J Neurol Neurosurg Psychiatry 1998;64:314-319.

17. Brooks DJ. Morphological and functional imaging studies on the diagnosis and progression of Parkinson's disease. J Neurol 2000;247(suppl 2):II11-II18.

18. Fearnley JM, Lees AJ. Ageing and Parkinson's disease: substantia nigra regional selectivity. Brain 1991;114:22832301.

19. Abbott RD, Petrovitch H, White LR, et al. Frequency of bowel movements and the future risk of Parkinson's disease. Neurology 2001;57:456-462.

20. Shiba M, Bower JH, Maraganore DM, et al. Anxiety disorders and depressive disorders preceding Parkinson's disease: a case-control study. Mov Disord 2000;15:669-677.

21. Ishihara $\mathrm{L}, \mathrm{Brayne} \mathrm{C}$. What is the evidence for a premorbid parkinsonian personality: a systematic review. Mov Disord 2006;21:1066-1072.

22. Braak H, Del Tredici K, Rub U, de Vos RA, Jansen Steur EN, Braak E. Staging of brain pathology related to sporadic Parkinson's disease. Neurobiol Aging 2003;24:197-211.

23. Braak H, Ghebremedhin E, Rub U, Bratzke H, Del Tredici K. Stages in the development of Parkinson's disease-related pathology. Cell Tissue Res 2004;318:121-134.
24. Lu J, Sherman D, Devor M, Saper CB. A putative flip-flop switch for control of REM sleep. Nature 2006;441:589594.

25. Kaufmann H, Nahm K, Purohit D, Wolfe D. Autonomic failure as the initial presentation of Parkinson disease and dementia with Lewy bodies. Neurology 2004;63:1093-1095.

26. Larner AJ, Mathias CJ, Rossor MN. Autonomic failure preceding dementia with Lewy bodies. J Neurol 2000;247: 229-231.

27. Yamanaka Y, Asahina M, Hiraga A, Sakakibara R, Oka H, Hattori T. Over 10 years of isolated autonomic failure preceding dementia and Parkinsonism in 2 patients with Lewy body disease. Mov Disord 2007;22:595-597.

28. Miyamoto T, Miyamoto M, Inoue Y, Usui Y, Suzuki K, Hirata K. Reduced cardiac 123I-MIBG scintigraphy in idiopathic REM sleep behavior disorder. Neurology 2006; 67:2236-2238.

29. Vendette M, Gagnon JF, Decary A, et al. REM sleep behavior disorder predicts cognitive impairment in Parkinson disease without dementia. Neurology 2007;69: 1843-1849.

30. Sinforiani E, Pacchetti C, Zangaglia R, Pasotti C, Manni R, Nappi G. REM behavior disorder, hallucinations and cognitive impairment in Parkinson's disease: a two-year follow up. Mov Disord 2008;23:1441-1445.

31. Schenck CH, Bundlie SR, Mahowald MW. REM behavior disorder (RBD): delayed emergence of parkinsonism and/or dementia in $65 \%$ of older men initially diagnosed with idiopathic RBD, and an analysis of the minimum \& maximum tonic and/or phasic electromyographic abnormalities found during REM sleep. Sleep 2003;26(suppl):A316.

\section{Activate Your Online Subscription}

Go to www.neurology.org and click on "Activate/Manage Your Subscription" (in left-hand column under "Journal Resources."). Then click on the "Activate Your Individual Member or NonMember Subscription" link and follow the online instructions.

\section{The NEW Neurology ${ }^{\circledR}$ online offers:}

- Sign up for Table of Contents and Topic Alerts

- "Personal folders" for articles and searches

- Resident and Fellow subsite

- Links to Neurology Now ${ }^{\circledR}$, Neurology Today ${ }^{\circledR}$, and Continuum $^{\circledR}$

- Mobile device download link

- Detailed podcast descriptions
- RSS Feeds of current issue and podcasts

- AAN web page links

- Social media including Facebook and Twitter links

- Increased search capability

- Enhanced navigation format

- Highlighted articles 


\section{Neurology}

REM sleep behavior disorder preceding other aspects of synucleinopathies by up to half a century

D.O. Claassen, K.A. Josephs, J.E. Ahlskog, et al.

Neurology 2010;75;494-499 Published Online before print July 28, 2010

DOI 10.1212/WNL.0b013e3181ec7fac

This information is current as of July 28, 2010

Neurology ${ }^{\circledR}$ is the official journal of the American Academy of Neurology. Published continuously since 1951, it is now a weekly with 48 issues per year. Copyright. All rights reserved. Print ISSN: 0028-3878. Online ISSN: 1526-632X.

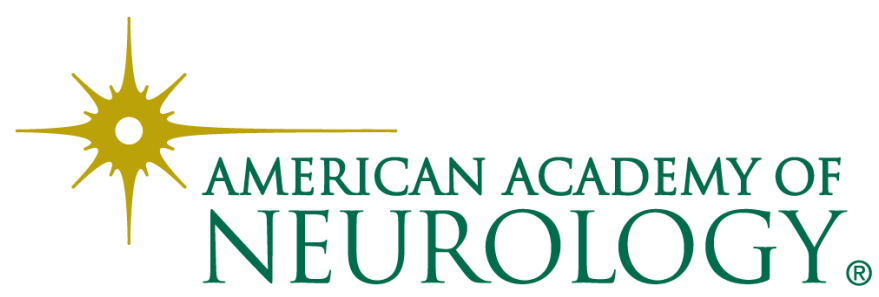




\section{Updated Information \& Services}

\section{Supplementary Material}

\section{References}

Citations

Subspecialty Collections

\section{Permissions \& Licensing}

Reprints including high resolution figures, can be found at: http://n.neurology.org/content/75/6/494.full

Supplementary material can be found at: http://n.neurology.org/content/suppl/2011/01/18/WNL.0b013e3181ec7f ac.DC1 http://n.neurology.org/content/suppl/2011/04/18/WNL.0b013e3181ec7f ac.DC2

This article cites 30 articles, 12 of which you can access for free at: http://n.neurology.org/content/75/6/494.full\#ref-list-1

This article has been cited by 11 HighWire-hosted articles: http://n.neurology.org/content/75/6/494.full\#\#otherarticles

This article, along with others on similar topics, appears in the following collection(s):

Dementia with Lewy bodies

http://n.neurology.org/cgi/collection/dementia_with_lewy_bodies Multiple system atrophy

http://n.neurology.org/cgi/collection/multiple_system_atrophy

\section{Parasomnias}

http://n.neurology.org/cgi/collection/parasomnias

Parkinson's disease with dementia

http://n.neurology.org/cgi/collection/parkinsons_disease_with_dementi a

Parkinson's disease/Parkinsonism

http://n.neurology.org/cgi/collection/parkinsons_disease_parkinsonism

Information about reproducing this article in parts (figures,tables) or in its entirety can be found online at:

http://www.neurology.org/about/about_the_journal\#permissions

Information about ordering reprints can be found online:

http://n.neurology.org/subscribers/advertise

Neurology ${ }^{\circledR}$ is the official journal of the American Academy of Neurology. Published continuously since 1951, it is now a weekly with 48 issues per year. Copyright . All rights reserved. Print ISSN: 0028-3878. Online ISSN: 1526-632X.

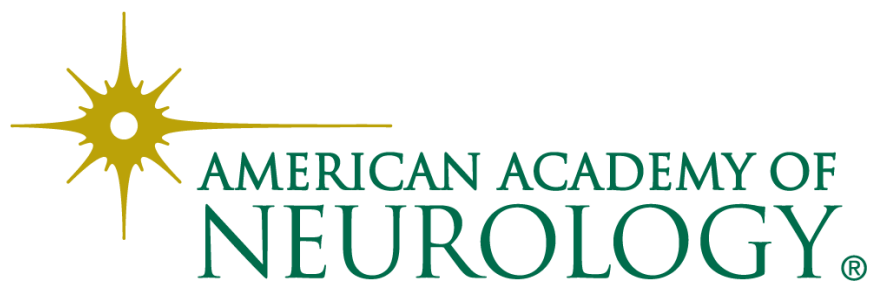

